\title{
Organizational Redundancy, Corporate Governance and Innovation Performance
}

\author{
Hui Zhang* \\ Shandong University of Finance and Economics, Jinan, 250014, China \\ *Corresponding auithor. E-mail: jessica880120@163.com
}

\begin{abstract}
Technology mergers and acquisitions is an important way for enterprises to obtain external technology resources and improve their core competitiveness. This paper takes Chinese listed companies as the research objects to explore the impact mechanism of the organizational redundancy on innovation performance. The results show that organizational redundancy has a significant 'U' effect on innovation performance of technology M \& A enterprises, and the impact of organizational redundancy on innovation performance of technology M \& A enterprises will be weakened with the continuous improvement of corporate governance level.
\end{abstract}

Keywords: Organizational redundancy, Innovation performance, Corporate governance.

\section{INSTRUCTION}

In the context of innovation driven development, innovation is very important for the enterprises survival and development as an important driving force for economic growth. With the increasingly fierce competition among enterprises, technology M \& A can obtain the technical knowledge and R \& D resources of the target enterprises in a short period of time, so it has gradually become one of the important ways for Chinese enterprises to improve their innovation ability.

Organizational redundancy refers to a kind of valuable resources that can be used directly or indirectly, which is more than necessary for enterprise production and operation. Previous studies have shown that technology $\mathrm{M} \& \mathrm{~A}$ is a complex organizational change activity for both parties, and its impact on innovation performance is also affected by many factors. This kind of change often consumes a lot of resources and reduces the resource commitment of management to innovation activities[1]. Therefore, in the complex organizational change of technology M \& A, it is of great theoretical and practical significance to explore the influence mechanism of organizational redundancy on the enterprises innovation performance. The internal governance not only directly affects the company operation, but also indirectly affects the enterprise redundant resource utilization behaviors by influencing the managers decision-making and enterprise strategy making. As an important arrangement of modern enterprise system, corporate governance can reduce various agency problems, form an effective endogenous incentive mechanism, and promote enterprises to improve their performance. Previous studies have focused on exploring the impact of a single dimension of corporate governance on enterprise innovation performance, such as the size of the directors board, management incentives [2], while ignoring the overall effectiveness mechanism of corporate governance on enterprise innovation performance.

In view of this, this paper discusses the influence of organizational redundancy on innovation performance of technology M \& A enterprises. On this basis, it analyzes the regulatory effect of corporate governance in the impact of organizational redundancy on innovation performance, so as to provide theoretical reference for listed companies in China to make $\mathrm{M} \& \mathrm{~A}$ decisions, integrate and make full use of redundant resources, and improve innovation performance.

\section{THEORETICAL ANALYSIS AND HYPOTHESIS PROPOSAL}

\subsection{The Organizational Redundancy and Innovation Performance}

Some scholars propose that organizational redundancy can alleviate the potential conflict within the enterprise [3]. However, some scholars believe that organizational redundancy has both positive and 
negative effects on the enterprise innovation performance, that is to say, they show an inverted ' $U$ ' relationship. Generally speaking, when the enterprises hold less redundant resources, their innovation level is higher; when the accumulation of redundant resources exceeds the limited scope, the enterprises principal-agent problem becomes more and more serious, and the continuous increase of redundancy will only have a negative impact on the innovation performance. In addition, Guo and Chen (2010) propose that there is a significant ' $U$ ' relationship between organizational redundancy and innovation performance based on Chinese manufacturing enterprises [4].

It can be seen that the inconsistent conclusions indicate that the effect mechanism of organizational redundancy on innovation performance is relatively complex. Different organizational redundancy levels have different effects on innovation performance. Technology M \& A often leads to the interruption of $\mathrm{R}$ $\& \mathrm{D}$ process and organizational practices, which brings a certain degree of 'shock' to the organization. At the same time, the technology M \& A often consumes a lot of resources and reduces the resource commitment of management to innovation activities. When organizational redundancy is in the first stage, that is, when there are few internal redundant resources, technology M \& A consumes a lot of internal redundant resources, which leads to the failure of enterprises to invest enough resources for innovation activities, and the obstacles of insufficient resources make it difficult for enterprises to innovate. In addition, the managers may use various means and methods to increase redundancy, so as to increase the freedom of their own power and maintain the necessary flexibility of the department. The activities of managers seeking to increase redundancy further reduce the 'available' innovation resources of the enterprise, thus reducing the enterprise innovation possibility. Therefore, low organizational redundancy has a negative impact on enterprise innovation performance. This paper proposes the hypothesis H1a: when organizational redundancy is lower than the 'resource critical point', organizational redundancy has a significant negative impact on innovation performance of $\mathrm{M} \& \mathrm{~A}$ enterprises.

The main reason for enterprises to maintain organizational redundancy is to protect their key activities from environmental changes. With the increase of redundant resources, organizational redundancy enters the second stage. On the one hand, technology $\mathrm{M}$ $\&$ A consumes a lot of resources, but the enterprise still has enough resources to carry out innovation activities. The redundant human, material and financial resources held by the enterprise can improve the enterprise resource integration ability, so as to improve the innovation performance $[5,6]$. On the other hand, the sufficient redundant resources can make up for the lack of systems and mitigate the impact of organizational change, improve the enterprises 'risk bearing capacity' 'and the implementation probability of high-risk technological innovation projects, and finally improve the innovation performance [7]. In view of this, this paper proposes the hypothesis H1b: when organizational redundancy is higher than the 'resource critical point', organizational redundancy has a significant positive impact on innovation performance of technology M \& A enterprises. To sum up, this study proposes the hypothesis H1: there is a significant ' $U$ ' relationship between organizational redundancy and innovation performance of technology M \& A enterprises.

\subsection{The Regulatory Role of Corporate Governance}

Previous studies have focused on the impact of corporate governance on enterprise value, capital cost, stock return, earnings quality, investment efficiency, etc. The high level of corporate governance can bring positive influence to the enterprise through the internal management mechanism. The agency theory shows that the essence of agency problem is the separation of ownership and control. In the case of separation of the two rights, it is very important to arrange governance mechanism to ensure the effectiveness of the contract. By supervising and controlling the managers, the shareholders can minimize the occurrence of management behaviors that damage the interests of shareholders. Under the condition of information asymmetry and incentive incompatibility, managers have the vast majority of residual control rights, and there is a large space for self-interest behavior due to the opportunistic motivation of managers. They may use the redundant resources of the organization to make decisions conducive to the maximization of personal interests, such as excessive expansion, excessive diversification, etc. A good corporate governance mechanism can effectively solve the moral hazard and adverse selection problems caused by the internal principal-agent relationship, alleviate the conflicts among the management, shareholders and creditors of the enterprise, and then form an effective endogenous incentive mechanism, improve the decision-making efficiency and operation efficiency of the enterprise, and finally promote the better use of the redundant resources [8]. Based on the above analysis, this paper proposes the hypothesis H2: corporate governance weakens the ' $\mathrm{U}$ ' shaped impact of organizational redundancy on innovation performance of technology $M \quad \& \quad A$ enterprises.

\section{RESEARCH DESIGN}

Based on CSMAR database, this paper selects A-share M \& A enterprises in Shanghai and Shenzhen stock markets from 2008 to 2015 as the research object. In view of the objectivity of $\mathrm{R} \& \mathrm{D}$ output indicators 
such as patent authorization and application, which are not easily affected by other factors, can objectively reflect the scientific research achievements of enterprises and represent the technological innovation strength of enterprises, this paper uses the number of patent applications to measure the enterprises innovation performance. In this paper, the organizational redundancy is measured by the average value of three indicators, such as current ratio, asset liability ratio and the ratio of sales, management and general expenses to sales revenue. This paper chooses multiple dimensions of corporate governance, and uses principal component analysis to build a comprehensive evaluation index of corporate governance quality. The larger the value is, the higher the quality of corporate governance is. For example, CEO not president, indirect ratio, share directors, share manager, share cont holder, director num, supervisor num and the sum of the top three executives' salaries. In addition, considering the influence of other factors on the enterprises innovation performance, this paper selects enterprise growth, financial performance, enterprise size and age as the control variables based on the existing research results.

\section{EMPIRICAL ANALYSIS}

Firstly, this paper examines the impact of organizational redundancy on innovation performance. As shown in Table 1, model 2 adds organizational redundancy variables on the basis of model 1 . The test results show that organizational redundancy has a significant negative impact on enterprise innovation performance $(\beta=-0.076, \mathrm{P}<0.01)$, so it is assumed that $\mathrm{H} 1 \mathrm{a}$ is tested. In model 3 , the quadratic term of organizational redundancy is added to model 2 . The results show that high level of organizational redundancy has a significant positive impact on innovation performance $(\beta=0.089, \mathrm{P}<0.01)$. Therefore, it is assumed that $\mathrm{H} 1 \mathrm{~b}$ is verified. It can be seen that there is a significant ' $U$ ' relationship between organizational redundancy and innovation performance, and the hypothesis $\mathrm{H} 1$ is verified.

Table 1. Empirical analysis results of the impact of organizational redundancy on innovation performance of technology M \& A enterprises

\begin{tabular}{|c|c|c|c|c|c|c|}
\hline \multirow{2}{*}{ variables } & \multicolumn{6}{|c|}{ innovation performance } \\
\hline & Model 1 & Model 2 & Model 3 & Model 4 & Model 5 & Model 6 \\
\hline enterprise growth & $\begin{array}{c}0.007 \\
(0.119)\end{array}$ & $\begin{array}{c}0.041 \\
(0.617)\end{array}$ & $\begin{array}{l}0.038 \\
(0.575)\end{array}$ & $\begin{array}{c}0.032 \\
(0.478)\end{array}$ & $\begin{array}{c}0.031 \\
(0.452)\end{array}$ & $\begin{array}{c}0.040 \\
(0.578)\end{array}$ \\
\hline roe & $\begin{array}{c}0.047 \\
(0.787)\end{array}$ & $\begin{array}{c}0.044 \\
(0.738)\end{array}$ & $\begin{array}{c}0.044 \\
(0.738)\end{array}$ & $\begin{array}{c}0.045 \\
(0.762)\end{array}$ & $\begin{array}{c}0.046 \\
(0.766)\end{array}$ & $\begin{array}{c}0.042 \\
(0.731)\end{array}$ \\
\hline enterprise age & $\begin{array}{l}-0.064^{*} \\
(-1.130)\end{array}$ & $\begin{array}{l}-0.073^{*} \\
(-1.167)\end{array}$ & $\begin{array}{l}-0.080^{*} \\
(-1.263)\end{array}$ & $\begin{array}{l}-0.077 * \\
(-1.227)\end{array}$ & $\begin{array}{l}-0.077 * \\
(-1.226)\end{array}$ & $\begin{array}{l}-0.085^{*} \\
(-1.336)\end{array}$ \\
\hline enterprise size & $\begin{array}{c}0.206 * * * \\
(3.335)\end{array}$ & $\begin{array}{c}0.191 * * * \\
(3.005)\end{array}$ & $\begin{array}{c}0.182 * * * \\
(2.830)\end{array}$ & $\begin{array}{c}\text { O.188*** } \\
(2.964)\end{array}$ & $\begin{array}{c}0.188 * * * \\
(2.943)\end{array}$ & $\begin{array}{c}0.017 * * * \\
(2.737)\end{array}$ \\
\hline year of acquisition & $\begin{array}{c}-0.030 \\
(-0.495)\end{array}$ & $\begin{array}{c}-0.029 \\
(-0.475)\end{array}$ & $\begin{array}{c}-0.027 \\
(-0.448)\end{array}$ & $\begin{array}{c}-0.017 \\
(-0.272)\end{array}$ & $\begin{array}{c}-0.016 \\
(-0.263)\end{array}$ & $\begin{array}{c}-0.016 \\
(-0.255)\end{array}$ \\
\hline $\begin{array}{c}\text { organizational } \\
\text { redundancy }(\mathrm{OR})\end{array}$ & & $\begin{array}{c}-0.076 * * * \\
(-2.096)\end{array}$ & $\begin{array}{c}-0.155 * * * \\
(-2.722)\end{array}$ & $\begin{array}{c}-0.070 * * * \\
(-2.006)\end{array}$ & $\begin{array}{c}-0.102 * * * \\
(-2.209)\end{array}$ & $\begin{array}{c}-0.201 * * * \\
(-3.262)\end{array}$ \\
\hline organizational redundancy $^{2}$ & & & $\begin{array}{c}0.089 * * * \\
(3.746)\end{array}$ & & & $\begin{array}{c}0.720 * * * \\
(3.513)\end{array}$ \\
\hline corporate governance $(\mathbf{C G})$ & & & & $\begin{array}{c}0.066 \\
(1.088)\end{array}$ & $\begin{array}{c}0.064 \\
(1.031)\end{array}$ & $\begin{array}{c}0.063 \\
(1.307)\end{array}$ \\
\hline CG*OR & & & & & $\begin{array}{c}0.033 \\
(0.093)\end{array}$ & \\
\hline $\mathrm{CG}^{*} \mathrm{OR}^{2}$ & & & & & & $\begin{array}{c}-0.596 * * \\
(-2.522)\end{array}$ \\
\hline $\mathbf{R}^{2}$ & 0.141 & 0.146 & 0.147 & 0.150 & 0.150 & 0.162 \\
\hline adjusted $R^{2}$ & 0.124 & 0.125 & 0.125 & 0.126 & 0.126 & 0.132 \\
\hline $\mathbf{F}$ & $3.420 * *$ & $3.518 * *$ & $3.778 * *$ & $3.909 * *$ & $3.907 * *$ & $3.983 * *$ \\
\hline
\end{tabular}

Note: $\mathrm{N}=286 . * \mathrm{P}<0.10, * * \mathrm{P}<0.05, * * * \mathrm{P}<0.01$ (double tail) 
In model 5 , the interaction between organizational redundancy and corporate governance is added. The results show that the interaction between organizational redundancy and corporate governance has a positive impact on innovation performance $(\beta=0.033)$, that is, corporate governance plays a certain regulatory role in the positive impact of organizational redundancy on innovation performance. In addition, the interaction between organizational redundancy square and corporate governance is added in model 6 . The results show that corporate governance has a significant moderating effect on the negative impact of organizational redundancy on corporate innovation performance $(\beta=-0.596, \mathrm{P}<0.05)$, that is to say, corporate governance weakens the 'U' relationship between organizational redundancy and innovation performance to some extent. Therefore, it is assumed that the $\mathrm{H} 2$ passes is verified partly.

\section{CONCLUSION AND ENLIGHTENMENT}

Based on the review of the relevant literature at home and abroad, this paper puts forward the theoretical model of this study. On this basis, this paper empirically tests the relationship between organizational redundancy and innovation performance of technology $\mathrm{M} \& \mathrm{~A}$ enterprises using data from 286 listed companies, and explores the regulatory role of corporate governance on the relationship between the organizational redundancy and innovation performance, in order to provide a new theoretical reference for enterprise management practice.

\subsection{There is a Significant ' $U$ ' Relationship between Organizational Redundancy and Innovation Performance of Technology $M \& A$ Enterprises}

When there are less redundant resources in technology M \& A enterprises, organizational redundancy has a negative impact on innovation performance; when organizational redundancy reaches the minimum resource line, organizational redundancy has a positive effect on enterprise performance. Organizational redundancy plays an important role in the improvement of innovation capability in technology $M$ \& A enterprises. The more abundant redundant resources are the more conducive to the improvement of innovation performance. Therefore, the enterprises need to carefully consider whether they have enough resource support before M \& A.

\subsection{The Corporate Governance Plays a Regulatory Role in the Influence of Organizational Redundancy on Innovation Performance of Technology M \& A Enterprises}

When the level of corporate governance is low, the corporate governance system is not perfect, and the efficiency of corporate governance is relatively low. Enterprises can't find and use redundant resources in time, so they can't play the role of internal governance, and finally reduce the negative impact of organizational redundancy on innovation performance of technology $\mathrm{M}$ $\&$ A enterprises. However, with the improvement of corporate governance level, it will inevitably lead to the integration and effective use of enterprise resources, reduce the dependence on redundant resources, and reduce the effect of redundant resources. Enterprises should choose appropriate internal governance mechanism according to their internal and external environment, integrate and optimize internal resources, so as to improve their own operation efficiency. For enterprises with more organizational redundancy and higher level of corporate governance, the failure risk of technology M \& A will be reduced. However, in the case of less organizational redundancy and low level of corporate governance, enterprises should be cautious in making $M$ \& A decisions.

\section{ACKNOWLEDGMENTS}

This paper is supported by the Social Science Youth Project of Shandong Province 'research on the sustainable growth mechanism of farmers' professional cooperatives in Shandong Province from the perspective of network embeddedness'20DGLJ08.

\section{REFERENCES}

[1] Han, B.S. 2017. Technology acquisitions and innovation: A review and research prospect. Business Management Journal 39(9):195-208.

[2] Wang, W.Q., Ma H.J. 2016. The relationship among acquirers' characteristics, R\&D investment and innovation performance in technology mergers and acquisitions. Studies in Science of Science 34(8):1203-1210.

[3] Cyert, R., March, J. 1963. A behavioral theory of the firm. Englewood Cliffs, NJ: Prentice-Hall.

[4] Guo, L.X., Chen, C.M. 2010. Research on the relationship between organizational slack and enterprises' technological innovation performance-An empirical analysis based on the panel data of the Chinese listed companies sample in China. Science of Science and Management of S.\&T. 31(11):52-60.

[5] Wen, C.Y., Liu, Z.X. 2011. The impact of technological M\&A on innovative performance of high-tech listed companies. Science Research Management 32(5):1-7+28.

[6] Li, Y., Zhang, C., Wang, L.J. 2016. A study on relations between technological M\&A modes, technical disparity and innovation performance. 
Science and Technology Management Research 36(18):192-197.

[7] Tan, J., Pen, M. 2003. Organizational slack and firm performance during economic transitions: Two studies from an emerging economy. Strategic Management Journal (24):1249-1264.
[8] Chen, X.H., Yin, Z., Zeng, J.H. 2007. The board governance, enterprise scale and growing quality_Evidence from the listed SMEs in China. Journal of East China Normal University (Philosophy and Social Sciences) 39(3):115-120. 